(C) 2014 IEEE. Personal use of this material is permitted. Permission from IEEE must be obtained for all other uses, in any current or future media, including reprinting/republishing this material for advertising or promotional purposes, creating new collective works, for resale or redistribution to servers or lists, or reuse of any copyrighted component of this work in other works. 


\title{
Managing Supply Disruption in a Three-Tier Supply Chain with Multiple Suppliers and Retailers
}

\author{
S. K. Paul, R. A. Sarker, D. L. Essam \\ School of Engineering and Information Technology \\ University of New South Wales, Canberra, Australia \\ (sanjoy.paul@student.adfa.edu.au,r.sarker@adfa.edu.au,d.essam@adfa.edu.au)
}

\begin{abstract}
In this paper, a supply disruption management model is introduced in a three-tier supply chain with multiple suppliers and retailers, where the system may face sudden disruption in its raw material supply. At first, we formulated a mathematical model for ideal conditions and then reformulated it to revise the supply, production and delivery plan after the occurrence of a disruption, for a future period, to recover from the disruption. Here, the objective is to minimize the total cost during the recovery time window while being subject to supply, capacity, demand, and delivery constraints. We have also proposed an efficient heuristic to solve the model and the results have been compared, with another established solution approach, for a good number of randomly generated test problems. The comparison showed the consistent performance of our developed heuristic. This paper also presents some numerical examples to explain the usefulness of the proposed approach.
\end{abstract}

\section{Keywords - Heuristic, supply chain, supply disruption}

\section{INTRODUCTION}

In the modern business era, supply chains are an important part of many businesses. A standard supply chain network consists of suppliers, manufacturers and retailers. Suppliers supply raw materials to manufacturers and after processing in a manufacturing plant, final products are delivered to retailers according to their demand. In reality, a supply chain can face many uncontrollable problems, such as production and supply disruption [1]. Without a proper response to those problems, a supply chain system can be imbalanced, and an organization can consequently face huge financial loss, as well as loss of goodwill.

Over the last half a century, supply chains have become one of the most popular research topics in operations research and computer science. A few examples of such research under ideal conditions, include: a single product, single warehouse and multiple retailers based distribution supply chain system [2], single manufacturer and single retailer supply chain model with demand and manufacturing cost as fuzzy variables [3], a single period and two-stage supply chain coordination problem [4] and a three-stage supply chain consisting of single supplier, manufacturer and retailer which produces a combination of perfect and imperfect quality items [5]. Recently, Pal et al. [6] developed an inventory model for multiple items produced by a manufacturer and considered multiple suppliers and multiple retailers with deterministic demand.
The above researches, along with many others, were carried out under ideal conditions. But in real life situations, a supply chain network can face a sudden disruption in any of its entities (node) and routes (arc). Any disruption may involve production capacity loss, raw material loss, product loss, delayed delivery, customer desatisfaction, higher product cost, loss of customers and reputation damage in the wider community. So an appropriate recovery plan from a disruption can improve a situation. In the literature, a few studies have been found which proposed a recovery plan after the occurrence of a disruption. Xia et al. [7] formulated a nonlinear programming model for managing disruption in a production and inventory control system. Hishamuddin et al. [8] extended the model of Xia et al. [7] for managing production disruption in a single-stage production inventory system that considered both back order and lost sales options. Recently, this back order and lost sales concept was also applied to manage transportation [9] and supply [10] disruption in a two-stage supply chain, which consists of a single supplier and a single retailer. This concept was further extended to develop a real time disruption management model, for managing both a single and multiple production disruptions in a single-stage [11] and two-stage [12] production inventory system. A few other studies considered supply disruption while developing a supply chain model, for examples, Parlar and Perry [13] developed inventory models that considered supplier availability with deterministic product demand. A production-inventory model that considered back orders under random supply disruptions was developed in [14] and was modelled as a Markov chain. Over the last few years, a few other supply chain disruption management models have been developed in [15] - [18].

From the literature review, it is clear that most research developed supply chain models under ideal conditions. Although a few of them considered production and supply disruption while developing recovery models, most of them considered single supplier and single retailer, which limits the applicability of such studies. To overcome this limitation, this paper develops a quantitative model to recover from a supply disruption, for a three-tier supply chain with multiple suppliers and multiple retailers. To do that, we have formulated a new mathematical model and proposed a heuristic approach, which considers both back orders and lost sales options, to obtain the optimal recovery plan after the occurrence of any supply disruption. 


\section{PROBLEM DESCRIPTION}

This paper considers a three-tier supply chain network with multiple raw material suppliers, a single manufacturer, and multiple retailers. We assume that each supplier supplies one type of raw material. That means the number of suppliers is equal to the number of different types of raw materials required in the production process. The products are produced in batches in a single manufacturing plant. After production, the products are delivered to the retailers according to their demand. In an ideal plan, the optimal supply, production and delivery quantities are $q_{i}, Q$ and $Q_{j}$ respectively, which is shown as a solid line in Fig. 1. However, the system may face a sudden supply disruption at any time. To manage the system efficiently, it is necessary to generate a recovery plan after the occurrence of a disruption. In Fig. 1, after the supply disruption, a recovery plan is proposed to revise the supply $\left(X_{k i}\right)$, production $\left(Y_{k}\right)$ and delivery $\left(Z_{k j}\right)$ quantities during the recovery time window, which is shown as a dashed line. The objective is to minimize the total cost during the recovery time window subject to supply, production capacity, demand, and delivery constraints.

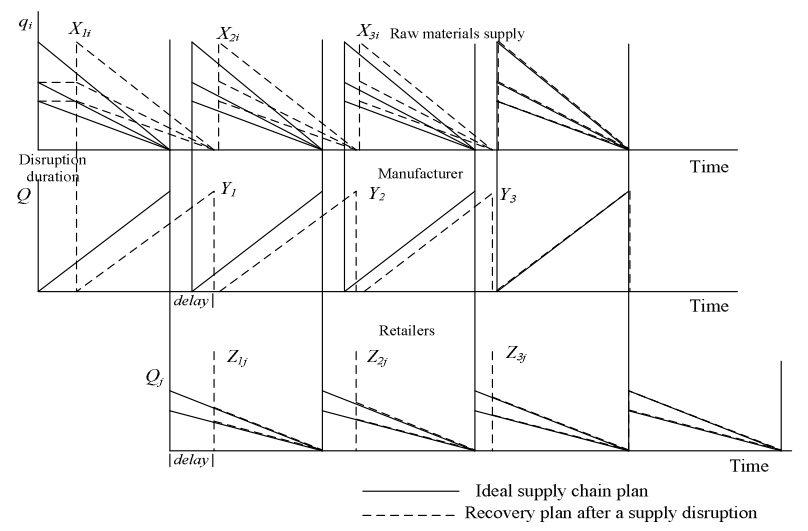

Fig. 1. Disruption recovery plan

A supply disruption can be defined as any form of interruption in the raw material supply that may be caused due to delay, unavailability, or any other form of disturbance. The recovery/revised plan is a new schedule that includes the revised supply, production and delivery quantities in each cycle, for future periods, while ensuring the minimization of the total cost in the recovery time window. The number of future cycles allocated to return to the original schedule from the disrupted cycle, defines the recovery time window, and is decided by the management of the organization. As we assume that the production rate is higher than the demand rate, there is an idle timeslot between any two consecutive production cycles. If the raw material supply is interrupted for a time period, known as disruption duration, the utilization of the idle timeslots, in future production cycles, may help to recover from the disruption. However, it may involve costly backorder and/or lost sales due to a long disruption duration and delayed production and delivery.

\section{A. Notations used in the Study}

The following notations are used in this study.

$D_{j} \quad$ Annual demand of the final product of retailer $j$

$D$ Annual total demand of the final product $=\sum_{j=1}^{J} D_{j}$

$d_{i} \quad$ Annual demand of raw material $i$

$B_{m}$ Back order cost for the manufacturer (\$ per unit per unit time)

$B_{r} \quad$ Back order cost for retailer (\$ per unit per unit time)

$B_{q k j}$ Back order quantity of retailer $j$ during the $k^{\text {th }}$ cycle

$L_{m}$ Lost sales cost for the manufacturer (\$ per unit)

$L_{r} \quad$ Lost sales cost for retailer (\$ per unit)

$H_{1 i}$ Holding cost of raw material $i$ (\$ per unit per year)

$\mathrm{H}_{2}$ Holding cost of the final product at the manufacturer (\$ per unit per year)

$H_{3 j}$ Holding cost of retailer $j$ (\$ per unit per year)

$N_{i}$ Units of raw material $i$ required to produce one unit of the final product

$K$ Number of cycles in the revised plan - known from management

$P \quad$ Annual production rate $(P>D)$

$Q$ Production lot size

$q_{i}$ Supply lot size of raw material $i$

$Q_{j} \quad$ Delivery lot size of the final product for retailer $j$

$S_{1 i}$ Ordering cost of raw material $i$ (\$ per order)

$S_{2}$ Set-up cost of the manufacturer (\$ per order)

$S_{3 j}$ Ordering cost of retailer $j$ (\$ per order)

$s_{t} \quad$ Set-up time after the production of a lot

$T_{i d l e}$ Idle time after the production of a lot $=\frac{Q}{D}-\frac{Q}{P}-S_{t}$

$T_{d n}$ Supply disruption duration of the $n^{\text {th }}$ raw material

$X_{k i}$ Supply lot size of raw material $i$ in the revised plan

$Y_{k}$ Production lot size in the revised plan

$Z_{k j}$ Delivery lot size of the final product to retailer $j$ in the revised plan

\section{B. Assumptions of the Study}

We have made the following assumptions:

i. The production rate is greater than the demand rate.

ii. A single type of item is produced in the system.

iii. The number of suppliers depends on the number of raw material types. Each supplier supplies one type of raw material.

iv. The recovery plan is started just after the ending point of a disruption.

\section{MODEL FORMULATION}

In this section, we develop a mathematical model, that considers supply disruption. First, we derive the equations for economic lot sizes $\left(q_{i}, Q\right.$ and $\left.Q_{j}\right)$ under ideal conditions, and then the relevant cost functions after the occurrence of a disruption. Finally, we formulate the disruption recovery problem as a constrained optimization problem that minimizes the total cost during the recovery time window, subject to supply, production capacity, demand, and delivery constraints. In this case, the decision variables are the supply, production and delivery quantities in each cycle during the recovery time window. 


\section{A. Formulation for the Ideal Plan}

The economic lot sizes $\left(q_{i}, Q\right.$ and $\left.Q_{j}\right)$, under ideal conditions, are derived in this section. The optimal ideal plan is obtained to minimize the total annual holding, ordering and set-up cost.

Annual raw material holding cost $=\frac{Q D}{2 P} \sum_{i=1}^{I} N_{i} H_{1 i}$

Annual raw material ordering cost $=\frac{D}{Q} \sum_{i=1}^{I} S_{1 i}$

Manufacturer annual holding cost $=\frac{Q}{2} H_{2} \frac{D}{P}$

Manufacturer annual set-up cost $=\frac{D}{Q} S_{2}$

Retailer annual holding cost $=\frac{Q}{2 D} \sum_{j=1}^{J} D_{j} H_{3 j}$

Retailer annual ordering cost $=\frac{D}{Q} \sum_{j=1}^{J} S_{3 j}$

Total cost,

$$
\begin{aligned}
T C= & \frac{Q D}{2 P} \sum_{i=1}^{I} N_{i} H_{1 i}+\frac{D}{Q} \sum_{i=1}^{I} S_{1 i}+\frac{Q}{2} H_{2} \frac{D}{P}+\frac{D}{Q} S_{2}+ \\
& \frac{Q}{2 D} \sum_{j=1}^{J} D_{j} H_{3 j}+\frac{D}{Q} \sum_{j=1}^{J} S_{3 j}
\end{aligned}
$$

Now, to minimize the total cost, $\frac{d}{d Q}(T C)=0$

After simplifying, the optimal ideal plan is obtained from $(8)-(10)$.

$$
\begin{aligned}
& Q=\sqrt{\frac{2 D\left(\sum_{i=1}^{I} S_{1 i}+S_{2}+\sum_{j=1}^{J} S_{3 j}\right)}{\frac{D}{P} \sum_{i=1}^{I} N_{i} H_{1 i}+\frac{H_{2} D}{P}+\frac{1}{D} \sum_{j=1}^{J} D_{j} H_{3 j}}} \\
& q_{i}=N_{i} Q \\
& Q_{j}=\frac{Q D_{j}}{D}
\end{aligned}
$$

\section{B. Formulation for the Recovery Plan}

In this section, we derive the recovery cost function that covers only the duration of the recovery time window. The costs involved, are the holding, set-up, ordering, back order, and lost sales. Back order is the portion of an order that cannot be delivered at the scheduled time, but that will be delivered at a later date when available, and back order cost is determined as the unit back order cost multiplied by back order units and it's time delay [11]. When there is demand, but the item is out of stock and the customer will not wait for the stock to be replenished, lost sales cost exists. Lost sales cost is determined as unit lost sales cost multiplied by lost sales units [12].

\section{B.1 Different Costs in the Recovery Plan}

Raw material holding cost

$=\sum_{i=1}^{I} \frac{X_{1 i}}{2} H_{1 i} \frac{Y_{1}}{P}+\sum_{\forall i \neq n} X_{1 i} T_{d n} H_{1 i}+\sum_{k=1}^{K} \sum_{i=2}^{I} \frac{X_{k i}}{2} H_{1 i} \frac{Y_{k}}{P}$

Raw material ordering cost $=K \sum_{i=1}^{I} S_{1 i}$

Manufacturer holding cost $=\sum_{k=1}^{K} \frac{Y_{k}^{2}}{2 P} H_{2}$

Manufacturer ordering cost $=K S_{2}$

Manufacturer back order cost

$=B_{m} \sum_{k=1}^{K} Y_{k}$. delay $_{k}$

Where, delay $_{k}=T_{d n}+\sum_{i=1}^{k} \frac{Y_{i}}{P}+(k-1) s_{t}-\frac{(k-1) Q}{D}-\frac{Q}{P}$

Manufacturer lost sales cost $=L_{m}\left(K Q-\sum_{k=1}^{K} Y_{k}\right)$

Retailer holding cost $=\sum_{k=1}^{K} \sum_{j=1}^{J} \frac{\left(Z_{k j}-B_{q k j}\right)^{2}}{2 D_{j}} H_{3 j}$

Retailer ordering cost $=K \sum_{j=1}^{J} S_{3 j}$
Retailer back order cost $=B_{r} \sum_{k=1}^{K} \sum_{j=1}^{J} \frac{\text { delay }_{k}}{2} B_{q k j}$

Retailer lost sales $=L_{r}\left(K \sum_{j=1}^{J} Q_{j}-\sum_{k=1}^{K} \sum_{j=1}^{J} Z_{k j}\right)$

\section{B.2 Final Mathematical Model}

The total cost function, which is the objective function, is obtained by adding all the costs presented in (11) - (20). Subject to the following constraints presented in (21) (28).

$Y_{k} \leq Q ; \forall k$ [To meet the delivery requirements]

$X_{k i} \leq q_{i} ; \forall i$ [Raw material supply constraint]

$Z_{k j} \leq Q_{j} ; \forall j$ [Final product delivery constraint]

delay $_{k} \geq 0 ; \forall k$ [Non-negative delay time]

$\frac{Q}{D}-\frac{Q}{P}-s_{t} \geq 0$ [Non-negative idle time]

$K Q-\sum_{k=1}^{K} Y_{k} \geq 0$ [Lost sales quantity constraint]

$\sum_{k=1}^{K} Y_{k} \leq P\left(K * \frac{Q}{D}-(K-1) * s_{t}-T_{d n}\right)$ [Production

capacity constraints]

$X_{k i}, Y_{k}, Z_{k j} \geq 0 ; \forall i, j, k$ [Non-negative constraint]

Proposition 1: For a given $H_{1 i}, H_{2}, H_{3 j}, S_{1 i}, S_{2}, S_{3 j}, D_{j}$, $P, B_{m}, B_{r}, L_{m}$ and $L_{r}$, the revised plan will only use the back order option if $T_{d n} \leq K T_{\text {idle }}$.

Proof: Idle time per cycle, $T_{\text {idle }}=\frac{Q}{D}-\frac{Q}{P}-s_{t}$. As there are $K$ cycles in the recovery plan, so the total idle time during the revised plan is $K T_{\text {idle }}$. The quantity to be produced during the idle time is $P K T_{i d l e}$.

Now, quantity loss during the disruption duration is $T_{d n} P$ The system will thus be able to recover by using only back order options, if the quantity to be produced during the idle time is greater than the quantity loss during the disruption duration.

So, $P K T_{\text {idle }} \geq T_{d n} P$, hence $T_{d n} \leq K T_{\text {idle }}$.

Proposition 2: For a given $H_{1 i}, H_{2}, H_{3 j}, S_{1 i}, S_{2}, S_{3 j}, D_{j}$, $P, B_{m}, B_{r}, L_{m}$ and $L_{r}$, both back order and lost sales will exist in the revised plan if $T_{d n}>K T_{\text {idle }}$.

Proof: This is the opposite consequence of Proposition 1. Proposition 3: For a given $H_{1 i}, H_{2}, H_{3 j}, S_{1 i}, S_{2}, S_{3 j}, D_{j}$, $P, B_{m}, B_{r}, L_{m}$ and $L_{r}$, the revised plan will only use the lost sales option if $\left(B_{m}+B_{r}\right)\left(\frac{Q}{D}-\frac{Q}{P}-s_{t}\right)>\left(L_{m}+L_{r}\right)$.

Proof: Idle time per cycle $=\frac{Q}{D}-\frac{Q}{P}-s_{t}$ and total back order cost per unit per unit time $=B_{m}+B_{r}$. So, back order cost per unit $=\left(B_{m}+B_{r}\right)\left(\frac{Q}{D}-\frac{Q}{P}-s_{t}\right)$

Now, lost sales cost per unit $=\left(L_{m}+L_{r}\right)$. Hence if $\left(B_{m}+B_{r}\right)\left(\frac{Q}{D}-\frac{Q}{P}-s_{t}\right)>\left(L_{m}+L_{r}\right)$, then the back order cost will be higher than the lost sales cost, so it is favorable that the revised plan will only use the lost sales option.

Proposition 4: For a given $H_{1 i}, H_{2}, H_{3 j}, S_{1 i}, S_{2}, S_{3 j}, D_{j}$, $P, B$ and $L$, the back order quantity of retailer to its customers, $\quad B_{q k j}=Z_{k j}-D_{j}\left(\frac{Q}{D}-\right.$ delay $\left._{k}\right)$; if $Z_{k j} \geq$ $D_{j}\left(\frac{Q}{D}-\right.$ delay $\left._{k}\right) \quad$ and $\quad B_{q k j}=0 ;$ if $Z_{k j}<D_{j}\left(\frac{Q}{D}-\right.$ delay $\left._{k}\right)$.

Proof: After a disruption, the delay time for delivering the final product of the $k^{\text {th }}$ cycle to a retailer is delay $y_{k}$. 
So, the remaining period of the demand cycle is $\left(\frac{Q}{D}-\right.$ delay $\left._{k}\right)$. The demand during the remaining period for retailer $j$ is $D_{j}\left(\frac{Q}{D}-\right.$ delay $\left._{k}\right)$. Now, the quantity received by retailer $j$ in the $k^{t h}$ cycle is $Z_{k j}$. If $Z_{k j} \geq D_{j}\left(\frac{Q}{D}-\right.$ delay $\left._{k}\right)$, then the excess quantity than $D_{j}\left(\frac{Q}{D}-\right.$ delay $\left._{k}\right)$ should be back ordered. So, the retailer back order quantity, $B_{q k j}=Z_{k j}-D_{j}\left(\frac{Q}{D}-\right.$ delay $\left._{k}\right)$ and if $Z_{k j}<$ $D_{j}\left(\frac{Q}{D}-\right.$ delay $\left._{k}\right)$, then the retailer back order quantity, $B_{q k j}=0$, because back orders are no longer needed in this condition.

\section{SOLUTION APPROACH}

In this section, a heuristic is developed to solve the developed model. For experimentation, we have generated the test problems by using a uniformly random distribution. To judge the quality of the heuristic solutions, the model is also solved by applying a pattern search technique, which is a standard search algorithm for solving constrained optimization problems [12]. Both the heuristic and the pattern search technique were coded in MATLAB R2012a, and were executed on an Intel core i7 processor with $8.00 \mathrm{~GB}$ RAM and a $3.40 \mathrm{GHz}$ CPU.

\section{A. Proposed Heuristic}

Step 1: Input all information about the ideal system.

Step 2: Determine $Q, q_{i}$ and $Q_{j}$ for the optimal ideal plan by using (8)(10) and also determine production time, cycle time and idle time. Step 3: Input disruption information, such as: disrupted raw material, disruption duration and recovery period.

Step 4: If $\left(B_{m}+B_{r}\right)\left(\frac{Q}{D}-\frac{Q}{P}-s_{t}\right) \leq\left(L_{m}+L_{r}\right)$ and $T_{d n} \leq K * T_{\text {idle }}$, then

$Y_{k}=Q ; \forall k$

$X_{k i}=N_{i} * Y_{k} ; \forall i, k$

$Z_{k j}=\frac{Y_{k^{*} D_{j}}}{D} ; \forall j, k$

If $T_{d n} \leq T_{i d l e}$, then delay $_{1}=T_{d n}+\frac{Y_{1}}{P}-\frac{Q}{P}$ delay $_{k}=0$; For $k=2,3, \ldots, K$

If $T_{\text {idle }}<T_{d n} \leq 2 T_{\text {idle }}$, then delay $_{1}=T_{d n}+\frac{Y_{1}}{P}-\frac{Q}{P}$ delay $_{2}=T_{d n}+\frac{Y_{1}+Y_{2}}{P}+s_{t}-\frac{Q}{D}-\frac{Q}{P}$ delay $_{k}=0$; for $k=3,4, \ldots ., K$

If $(K-1) T_{\text {idle }}<T_{d n} \leq K T_{\text {idle }}$, then delay $_{k}=T_{d n}+\sum_{i=1}^{k} \frac{Y_{i}}{P}+(k-1) s_{t}-\frac{(k-1) Q}{D}-\frac{Q}{P} ; \forall k$

Step 5: If $\left(B_{m}+B_{r}\right)\left(\frac{Q}{D}-\frac{Q}{P}-s_{t}\right) \leq\left(L_{m}+L_{r}\right)$ and $T_{d n}>K T_{i d l e}$, then

$Y_{1}=Q$

$Y_{2}=Q-P\left[T_{d n}-K *\left(\frac{Q}{D}-\frac{Q}{P}-s_{t}\right)\right]$

$Y_{k}=Q ;$ For $k=3,4, \ldots, K$

$X_{k i}=N_{i} * Y_{k} ; \forall i, k$

$Z_{k j}=\frac{Y_{k^{*} D_{j}}}{D} ; \forall j, k$

delay $_{k}=T_{d n}+\sum_{i=1}^{k} \frac{Y_{i}}{P}+(k-1) s_{t}-\frac{(k-1) Q}{D}-\frac{Q}{P} ; \forall k$

Step 6: If $\left(B_{m}+B_{r}\right)\left(\frac{Q}{D}-\frac{Q}{P}-s_{t}\right)>\left(L_{m}+L_{r}\right)$ then

$Y_{1}=Q-T_{d n} * P$

$Y_{k}=Q ;$ For $k=2,3, \ldots, K$

$X_{k i}=N_{i} * Y_{k} ; \forall i, k$

$Z_{k j}=\frac{Y_{k^{*} D_{j}}}{D} ; \forall j, k$ $\operatorname{delay}_{k}=0 ; \forall k$

Step 7: Determine the lost sales and back order quantities.

Step 8: Determine the different costs and record the results. Step 9: Stop.

\section{RESULTS ANALYSIS}

In this section, the results for both the ideal and recovery plans are discussed. For experimentation upon the disruption problem, we have generated and solved 90 random test problems. The results from both the heuristic and the pattern search are compared below.

\section{A. Ideal Plan}

The following data are considered to analyze the results for the ideal system.

$I=3 ; J=4 ; D_{j}=[15000,25000,20000,30000]$;

$P=100000 ; N_{i}=[1,1.5,1.25] ; H_{1 i}=[2,2.5,2.2]$;

$S_{1 i}=[100,80,120] ; H_{2}=3 ; S_{2}=150 ; H_{3 j}=[1.2,1.5$,

$1.7,1.4] ; S_{3 j}=[50,60,60,50] ; S_{t}=0.000228$

Using the (8) - (10), the ideal plan is obtained as follows.

$Q=3195.4 ; q_{i}=[3195.4,4793.1,3994.3]$; and

$Q_{j}=[532.6,887.6,710.1,1065.1]$

\section{B. Disruption Recovery Plan}

In this section, the results for managing supply disruption are analyzed. Although we have experimented on 90 random disruption test problems, for illustrative purpose, three sample instances are presented in Table I.

TABLE I

THREE SAMPLE INSTANCES

\begin{tabular}{ccc}
\hline $\begin{array}{c}\text { Disruption } \\
\text { Instance }\end{array}$ & $\begin{array}{c}\text { Disrupted Raw } \\
\text { Material }\end{array}$ & $\begin{array}{c}\text { Disruption } \\
\text { Duration }\end{array}$ \\
\hline 1 & 2 & 0.005 \\
2 & 1 & 0.015 \\
3 & 3 & 0.025 \\
\hline
\end{tabular}

The results to recover from the disruption is presented in Table II, which shows back order, lost sales, and total cost in the recovery plan, along with computational time.

TABLE II

THE RESULTS FOR THE THREE SAMPLE INSTANCES

\begin{tabular}{ccccc}
\hline $\begin{array}{c}\text { Disruption } \\
\text { Instance }\end{array}$ & $\begin{array}{c}\text { Total Back } \\
\text { Order Cost }\end{array}$ & $\begin{array}{c}\text { Total Lost } \\
\text { Sales Cost }\end{array}$ & Total Cost & $\begin{array}{c}\text { Comp. Time } \\
(\mathrm{Sec})\end{array}$ \\
\hline 1 & 439.270 & 0.00 & 7185.81 & 0.26 \\
2 & 2876.54 & 0.00 & 9723.25 & 0.23 \\
3 & 3872.65 & 33550.61 & 44105.85 & 0.14 \\
\hline
\end{tabular}

\section{Result Comparison}

To judge the quality of the solutions obtained from our proposed heuristic, the solutions of 90 test problems (as indicated earlier) were compared with the same obtained from the pattern search. The comparison showed that our proposed heuristic is capable of producing high quality solutions with little computational time, as presented in Table III. In terms of the quality of the solutions, the average deviation of results between the two 
approaches is only $0.0000029 \%$, which can be considered as negligible.

TABLE III

COMPARISON OF RESULTS

\begin{tabular}{ccc}
\hline Approach & Avg. Comp. Time (Sec) & $\begin{array}{c}\text { Avg. Dev. of } \\
\text { Results (\%) }\end{array}$ \\
\hline Heuristic & 0.19 & 0.0000029 \\
Pattern Search & 19.13 & \\
\hline
\end{tabular}

\section{Effect of Disruption Duration}

There is a significant effect of disruption duration on the back order, lost sales and total cost, which is presented in Fig. 2. In this analysis, only the disruption duration is changed and the remaining parameters are kept fixed as given in Section $\mathrm{V}$. The total cost increases with the disruption duration, because of the introduction of back orders and lost sales in the system. After the disruption duration $=0.016$, the total cost increases with a larger rate, because of the commencement of lost sales costs. The lost sales cost increases linearly after the disruption duration of 0.016 and before that the revised plan uses only the back order option. The back order cost also increases with the disruption duration, but the increment rate becomes lower after introducing the lost sales in the revised plan.

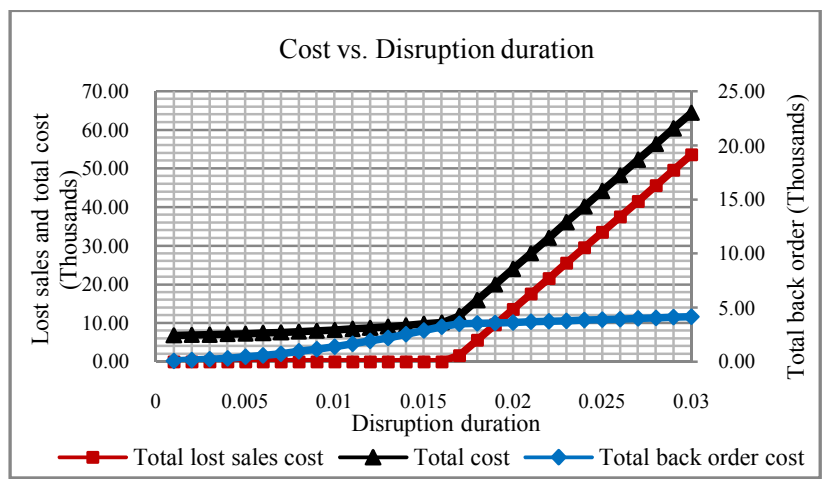

Fig. 2. Effect of disruption duration on the different costs

\section{CONCLUSIONS}

The main objective of this study, was to develop a recovery plan after the occurrence of a raw material supply disruption in a three-tier supply chain network, with multiple numbers of suppliers and retailers. A new mathematical and heuristic approach was developed to propose the optimal revised supply, production and distribution plan, during the recovery window, to minimize the effect of any disruption. The proposed heuristic results were compared with the results from a pattern search technique for a good number of randomly generated disruption test problems, and that showed the consistent performance of our proposed heuristic with little computational time. The proposed model offers a potentially very useful quantitative study to help decision makers to make prompt and accurate decisions with the optimal revised plan, whenever a sudden raw material supply disruption occurs in a supply chain system.

\section{REFERENCES}

[1] M. S. Sodhi, and S. Chopra, "Managing risk to avoid supply-chain breakdown," MIT Sloan management review, vol. 46, no. 1, pp. 53-61, 2004.

[2] D. Petrovic, Y. Xie, K. Burnham, and R. Petrovic, "Coordinated control of distribution supply chains in the presence of fuzzy customer demand," European Journal of Operational Research, vol. 185, no. 1, pp. 146-158, 2008.

[3] C. Zhou, R. Zhao, and W. Tang, "Two-echelon supply chain games in a fuzzy environment," Computers \& Industrial Engineering, vol. 55, no. 2, pp, 390-405, 2008.

[4] R. Xu, and X. Zhai, "Manufacturer's coordination mechanism for single-period supply chain problems with fuzzy demand," Mathematical and Computer Modelling, vol. 51, no. 5, pp. 693-699, 2010.

[5] S. S. Sana, "A production-inventory model of imperfect quality products in a three-layer supply chain," Decision Support Systems, vol. 50, no. 2, pp. 539-547, 2011.

[6] B. Pal, S. S. Sana, and K. Chaudhuri, "A three layer multiitem production-inventory model for multiple suppliers and retailers," Economic Modelling, vol. 29, no. 6, pp. 27042710, 2012.

[7] Y. Xia, M. H. Yang, B. Golany, S. M. Gilbert, and G. Yu, "Real-time disruption management in a two-stage production and inventory system," IIE transactions, vol. 36, no. 2, pp. 111-125, 2004.

[8] H. Hishamuddin, R. A. Sarker, and D. Essam, "A disruption recovery model for a single stage productioninventory system," European Journal of Operational Research, vol. 222, no. 3, pp. 464-473, 2012.

[9] H. Hishamuddin, R. A. Sarker, and D. Essam, "A recovery model for a two-echelon serial supply chain with consideration of transportation disruption," Computers \& Industrial Engineering, vol. 64, no. 2, pp. 552-561, 2013.

[10] H. Hishamuddin, R. A. Sarker, and D. Essam, "A recovery mechanism for a two echelon supply chain system under supply disruption," Economic Modelling, vol. 38, pp. 555563, 2014.

[11] S. K. Paul, R. Sarker, and D. Essam, "A disruption recovery model in a production-inventory system with demand uncertainty and process reliability," Lecture notes in Computer Science, vol. 8104, pp. 511-522, 2013.

[12] S. K. Paul, R. Sarker, and D. Essam, "Real time disruption management for a two-stage batch production-inventory system with reliability considerations," European Journal of Operational Research, vol. 237, no. 1, pp.113-128, 2014

[13] M. Parlar, and D. Perry, "Inventory models of future supply uncertainty with single and multiple suppliers," Naval Research Logistics, vol. 43, no.2, pp. 191-210, 1996.

[14] S. Özekici, and M. Parlar, "Inventory models with unreliable suppliers in a random environment," Annals of Operations Research, vol. 91, pp. 123-136, 1999.

[15] B. Tomlin, "On the value of mitigation and contingency strategies for managing supply chain disruption risks," Management Science, vol. 52, no. 5, pp. 639-657, 2006

[16] T. Wu, J. Blackhurst, and P. O'grady, "Methodology for supply chain disruption analysis," International Journal of Production Research, vol. 45, no.7, pp. 1665-1682, 2007.

[17] A. M. Ross, Y. Rong, and L.V. Snyder, "Supply disruptions with time-dependent parameters," Computers and Operations Research, vol. 35, no. 11, pp. 3504-3529, 2008.

[18] L. Qi, Z. J. M. Shen, and L. V. Snyder, "A continuousreview inventory model with disruptions at both supplier and retailer," Production and Operations Management, vol. 18, no. 5, pp. 516-532, 2009. 